\title{
Treatment of severe osteochondral defects of the knee by combined autologous bone grafting and autologous chondrocyte implantation using fibrin gel
}

\author{
Yvonne E. Könst • Rob J. Benink • Ron Veldstra • \\ Tjerk J. van der Krieke • Marco N. Helder • \\ Barend J. van Royen
}

Received: 11 July 2011/ Accepted: 10 January 2012/Published online: 3 February 2012

(C) The Author(s) 2012. This article is published with open access at Springerlink.com

\begin{abstract}
Purpose Severe symptomatic and unstable osteochondral defects of the knee are difficult to treat. A variety of surgical techniques have been developed. However, the optimal surgical technique is still controversial. We present a novel technique in which autologous bone grafting is combined with gel-type autologous chondrocyte implantation (GACI).

Methods Isolated severe osteochondral defects of the medial or lateral femoral condyle were treated by a twostep procedure. Firstly, chondrocytes were harvested during arthroscopy and cultured for 6 weeks. Secondly, a full thickness corticospongious autologuos bone graft, harvested from the medial or lateral femur condyle, is impacted in the defect and covered by GACI. The fibrin gel fills up to the exact shape of the chondral lesion and polymerizes within 3 min after application.
\end{abstract}

Y. E. Könst · R. J. Benink · R. Veldstra · T. J. van der Krieke Department of Orthopaedic Surgery, Gemini Ziekenhuis, Huisduinerweg 3, 1780 AT Den Helder, The Netherlands e-mail: yvonnekunst@hotmail.com

R. J. Benink

e-mail: rbenink@gemini-ziekenhuis.nl

R. Veldstra

e-mail: rveldstra@gemini-ziekenhuis.nl

T. J. van der Krieke

e-mail: tkrieke@gemini-ziekenhuis.nl

Y. E. Könst · M. N. Helder · B. J. van Royen ( $\square)$

Department of Orthopaedic Surgery,

VU University Medical Center, De Boelelaan 1117,

1081 HV Amsterdam, The Netherlands

e-mail: bj.vanroyen@vumc.nl

M. N. Helder

e-mail: mn.helder@vumc.nl
Results From 2009 to 2011, 9 patients, median age 35 years (range 23-47), were treated by the combined autologous bone grafting and GACI technique. Median defect size was $7.1 \mathrm{~cm}^{2}$ (range 2.5-12.0), and median depth of the lesion was $0.9 \mathrm{~cm}$ (range 0.8-1.2). Median follow-up was 9 months (range 6-12 months). Six patients were available for 12-month follow-up. The mean IKDC score showed a 6-month improvement from $35(\mathrm{SD} \pm 16)$ to $51(\mathrm{SD} \pm 18) \quad(n=9 ; \quad p=0.01), \quad$ and a 1-year improvement from $35(\mathrm{SD} \pm 16)$ to $57(\mathrm{SD} \pm 20)(n=6$; $p=0.03)$. The mean KOOS improved from $44(\mathrm{SD} \pm 16)$ to $62(\mathrm{SD} \pm 19)(n=9 ; p=0.07)$ at 6 -month follow-up and from $44(\mathrm{SD} \pm 16)$ to $65(\mathrm{SD} \pm 24)(n=6 ; p=0.1)$ at 12-month follow-up. There was one failure that needed conversion to a unicompartmental knee arthroplasty.

Conclusion Combined autologous bone grafting and GACI may offer an alternative surgical option for severe and unstable osteochondral defects of the knee.

Level of evidence IV.

Keywords Osteochondral defect Knee Bone graft . Fibrin gel · ACI

\begin{tabular}{|c|c|}
\hline \multicolumn{2}{|c|}{ Abbreviations } \\
\hline ACI & Autologous chondrocyte implantation \\
\hline ACI-P & $\begin{array}{l}\text { Autologous chondrocyte implantation using } \\
\text { periosteal membranes }\end{array}$ \\
\hline ACI-C & $\begin{array}{l}\text { Autologous chondrocyte implantation using } \\
\text { collagen membranes }\end{array}$ \\
\hline GACI & Gel-type autologous chondrocyte implantation \\
\hline IKDC & International knee documentation committee \\
\hline KOOS & Knee injury and osteoarthritis outcome score \\
\hline MRI & Magnetic resonance imaging \\
\hline ICRS & International cartilage repair society \\
\hline CPM & Continuous passive motion \\
\hline
\end{tabular}

Abbreviations

ACI Autologous chondrocyte implantation periosteal membranes collagen membranes

GACI Gel-type autologous chondrocyte implantation

IKDC International knee documentation committee

KOOS Knee injury and osteoarthritis outcome score

MRI Magnetic resonance imaging

CPM Continuous passive motion 


\section{Introduction}

Osteochondral defects are severe localized intra-articular defects of the cartilage and subchondral bone, leading to partial or complete detachment of the fragment. The knee joint is the most affected anatomical site [20, 26, 32]. Although König first described this lesion in 1887, the aetiology has not been clarified up to now [4, 17, 32].

Severe symptomatic and unstable osteochondral defects are difficult to treat. A variety of surgical techniques has been developed; however, the optimal surgical technique is still controversial [13, 27]. Fragment removal without subsequent repair may be considered in some cases $[1,24$, 36]. Nevertheless, current treatment modalities are more focused on restoration of the defect. Internal fixation of the unstable osteochondral defect with metal or resorbable screws is the first option of treatment [12, 22, 23]. When fixation is not amendable, autologous matrix-induced chondrogenesis with bone grafting [6] or mosaic osteochondral autograft transplantation is described to treat osteochondral defects $[15,16]$.

Currently, there is a growing interest in regenerative techniques, such as autologous chondrocyte implantation (ACI), in the management of articular lesions [7, 8, 21, 31, 34]. In ACI, a full thickness cartilage graft is harvested from a non-loadbearing site, and chondrocytes are isolated by extracellular matrix digestion and subsequently cultured for four to 6 weeks. Thereafter, the autologous chondrocytes are implanted in the cartilage defect by injection of the chondrocyte suspension under a sutured and sealed tibial periosteal (ACI-P) or a porcine collagen (ACI-C) patch. In severe osteochondral defects, however, both subchondral bone and articular cartilage are damaged. Reconstruction of both structures, bone and cartilage, is of paramount importance for optimal healing of the defect. Only few papers describe the treatment of osteochondral defects by combined bone grafting and ACI [5, 21, 25, 28]. Cancellous bone from the iliac crest or from the proximallateral part of the tibia is harvested and followed by the ACI-P or ACI-C procedure.

These ACI-P and ACI-C techniques, however, require securing of a periosteal membrane or collagen membrane to the normal cartilage edge by resorbable sutures and fibrin glue. Recently, the use of a gel-type ACI (GACI) has been introduced as an alternative ACI procedure for the treatment of focal articular cartilage defects in the knee that does not need any additional securing of the periosteal or collagen flap [10, 18, 19, 37]. The fibrin gel fills up to the exact shape of the chondral lesion and polymerizes within 3 min after application.

A novel technique for the treatment of severe symptomatic osteochondral defects of the knee by combined autologous bone grafting and ACI in fibrin gel (GACI) is presented. The objective of this study is to describe the technique and report our short-term results of the first patients treated by this technique.

\section{Materials and methods}

From March 2009 until December 2010, 9 patients, 3 men and 6 women, were treated for severe symptomatic and unstable isolated osteochondral defects of the lateral or medial femoral condyle by combined autologous bone grafting and GACI. All patients signed written informed consent before treatment. The median age at operation was 35 years (range 23-47), and the median follow-up was 9 months (range 6-12). Inclusion criteria for treatment were a history of long-term pain and swelling of the knee after exercise not responding to conservative treatment. Five patients suffered from a post-traumatic osteochondral defect, and four patients suffered from a symptomatic osteochondritis dissecans lesion. Plain radiographs and MRI were used to localize the osteochondral defect. The severity of the defect was staged by arthroscopy according to the International Cartilage Repair Society (ICRS) criteria [9]. The size and depth of the defect were measured in $\mathrm{mm}$ and expressed in $\mathrm{cm}$ allowing one decimal. The osteochondral defects of the medial or lateral femoral condyle were treated by a two-step procedure. Firstly, chondrocytes were harvested by arthroscopy and cultured for 6 weeks. Secondly, a full thickness corticospongious autologuos bone graft, harvested from the medial or lateral femur condyle, was impacted in the defect and covered by GACI. Two orthopaedic surgeons performed the surgical procedure (RB and RV).

Patient outcome was analysed using the international knee documentation committee (IKDC) evaluation form [2] and the knee injury and osteoarthritis outcome score (KOOS) [11] preoperative and at 3, 6, and 12 months postoperative. The IKDC consisted of three domains: symptoms, sport activities and function. Total score was limited from 0 to 100 points representing the disability of the patient, in which high scores indicate minimal disability and low scores indicate high limitations on the three domains. The KOOS questionnaire consisted of five domains: symptoms and stiffness, pain, activities of daily living, function in sports and recreational activities, and quality of life. Scores were transformed to a scale of 0-100 points, with 0 representing extreme knee problems and 100 representing no knee problems. Scores of each domain were added up and divided by the number of domains. Early MRI evaluation was performed 3 months postoperatively. 
Statistical analysis

Statistical analysis was done using a Wilcoxon rank test, and calculations were made using SPSS version 18.0. Statistical significance was defined as $p<0.05$.

Surgical procedure

During the initial arthroscopic staging of the defect, a cartilage biopsy was taken from the margin of the femoral condyle to obtain chondrocytes for culture expansion. The culturing process of the chondrocytes and the subsequent GACI procedure (Chondron ${ }^{\mathrm{TM}}$ ) were performed as described previously [10, 18, 19, 37].

After culturing of the chondrocytes for 6 weeks, the patients returned for a second-stage reconstruction of the osteochondral defect by combined autologous bone grafting and GACI procedure. All operations were performed under general or spinal anaesthesia, and a tourniquet was used. Prophylactic antibiotics, cefuroxime (cephalosporin, Zinacef ${ }^{(B)}$ ) 1,500 $\mathrm{mg} \mathrm{IV}$, were administered at the induction of anaesthesia, and a second, third and fourth dose of $750 \mathrm{mg}$ at 8,16 and $24 \mathrm{~h}$ postoperatively. Arthrotomy was performed via a midline incision, and the joint was approached medially or laterally depending on the location of the defect. Sclerotic bone and fibrous tissue in the bed of the defect were resected and debrided using a curette until bleeding cancelous bone and a stable cartilaginous rim were obtained (Fig. 1a, b). The defect was measured, and a template was created using a small piece of aluminium foil.

Bone harvesting for the reconstruction of the osseous defect was performed using the distal femur as source of autograft bone. The ipsilateral medial or lateral distal femur was reached using the same approach $2 \mathrm{~cm}$ above the articular edge "around the corner" (Fig. 1c). The template was placed on the periosteum of the distal femur condyle, and an outline 1-2 mm larger than the template was marked on the periosteum. Using an osteotome, a corticospongious bone graft was harvested en bloc in the same shape and size of the defect. Subsequently, the bone graft was impacted in the defect until its cortex levelled the subchondral plate (Fig. 1d) and perforated with superficial holes with a maximum depth and diameter of $2 \mathrm{~mm}$. Thereafter, the GACI procedure was performed to create the cartilage layer over the bone graft (Fig. 1e). During application, the cultured chondrocytes were mixed with thrombin and human fibrinogen (Beriplast ${ }^{\circledR}$; CSL Behring, Germany) in a 1:1 ratio. Polymerization of thrombin and fibrinogen alters the liquid cell-gel mixture into a dense fibrin structure in $3 \mathrm{~min}[10,18,19,37]$. The fibrin gel serves as a scaffold for the chondrocytes. After polymerization, stability of the fibrin gel is tested by repeated flexion and extension of the knee. Finally, the donor site is filled up with allogen bone graft (Netherlands Bonebank Foundation, NBF), and the synovium is sutured back in place. The arthrotomy is closed, and fascia and subcutis are sutured in layers. Postoperatively, the knee was splinted in extension, and the leg was elevated for $12 \mathrm{~h}$. Rehabilitation was supported by using a continuous passive motion (CPM) device during the first 6 weeks, for $6 \mathrm{~h}$ a day at regular intervals. Full weight bearing was allowed 8 weeks postoperative under supervision of a physiotherapist.

\section{Results}

Eight Patients were treated for unstable osteochondral defects of the medial femoral condyle, and 1 patient was treated for an unstable osteochondral defect of the lateral femoral condyle. All defects were staged ICRS grade III-IV. The median defect size was $7.1 \mathrm{~cm}^{2}$ (range 2.5-12.0), and the median depth of the lesion was $0.9 \mathrm{~cm}$ (range 0.8-1.2).

There were no postoperative complications. The mean IKDC score showed 6-month improvement from 35 $(\mathrm{SD} \pm 16)$ to $51(\mathrm{SD} \pm 18)(n=9 ; p=0.01)$, and a 1-year improvement from $35(\mathrm{SD} \pm 16)$ to $57(\mathrm{SD} \pm 20)$ $(n=6 ; p=0.03)$. The mean KOOS score improved from $44(\mathrm{SD} \pm 16)$ to $62(\mathrm{SD} \pm 19)(n=9$; n.s. $)$ at 6 -month follow-up and from $44(\mathrm{SD} \pm 16)$ to $65(\mathrm{SD} \pm 24)(n=6$; n.s.) at 1-year follow-up. MRI at 3 months postoperative demonstrates a diminishing demarcation zone of the transplanted bone graft, and a complete filling of the cartilage defect with repair tissue to the level of the adjacent cartilage (Fig. 2). The surface of the cartilage repair tissue was intact, displaying a homogeneous structure with an isointense signal at T1-weighted MRI with regard to the adjacent cartilage.

One patient suffered from persistent severe complaints. MRI at 6 months showed progressive multiple cyst formation of the entire distal femur outside the treated area. The affected knee of the patient was converted to an unicompartmental arthroplasty 1 year after initial surgery. Histology of the osteochondral biopsies taken from the centre of the defect, treated by combined autologous bone grafting and GACI and showed a homogeneous modulation zone containing a mixture of fibroblasts, progenitor cells and chondroblasts. Beneath this modulation zone, chondrocytes were found. The border zone of cartilage and bone showed a reactive process of adjacent bone, fibrotic tissue and osteoblasts. There were no signs of infection or osteonecrosis.

\section{Discussion}

The most important result to emerge from this study is that the presented surgical method makes it possible to treat 

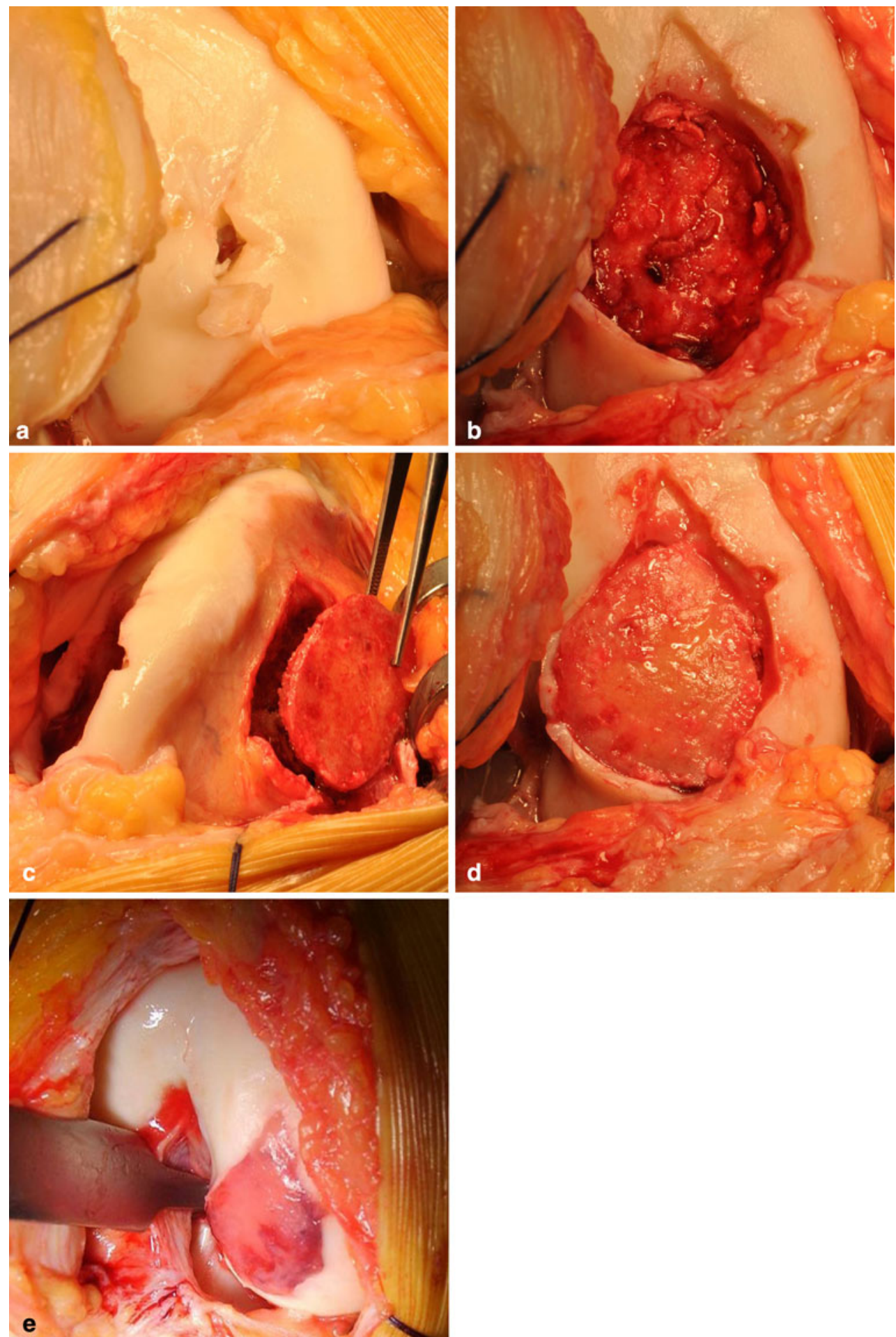

Fig. 1 a-e Surgical procedure of combined autologous bone grafting and autologous chondrocyte implantation in fibrin gel in an unstable osteochondral defect of the knee: a preoperative macroscopic aspect of the osteochondral defect of the right medial femoral condyle,

b resection of the cartilage defect and surface debridement of the bone defect, $\mathbf{c}$ harvesting autologous bone autograft "around the corner" of the cartilage edge, $\mathbf{d}$ impaction of the autologous bone graft and e implantation of autologous chondrocytes in fibrin gel

severe and unstable osteochondral defects of the femoral knee by repair tissue that resembles native corticospongious bone and articular cartilage. New in our study is the

combined use of autologous bone grafting and surface cartilage repair by GACI to reconstruct the osteochondral defect. 

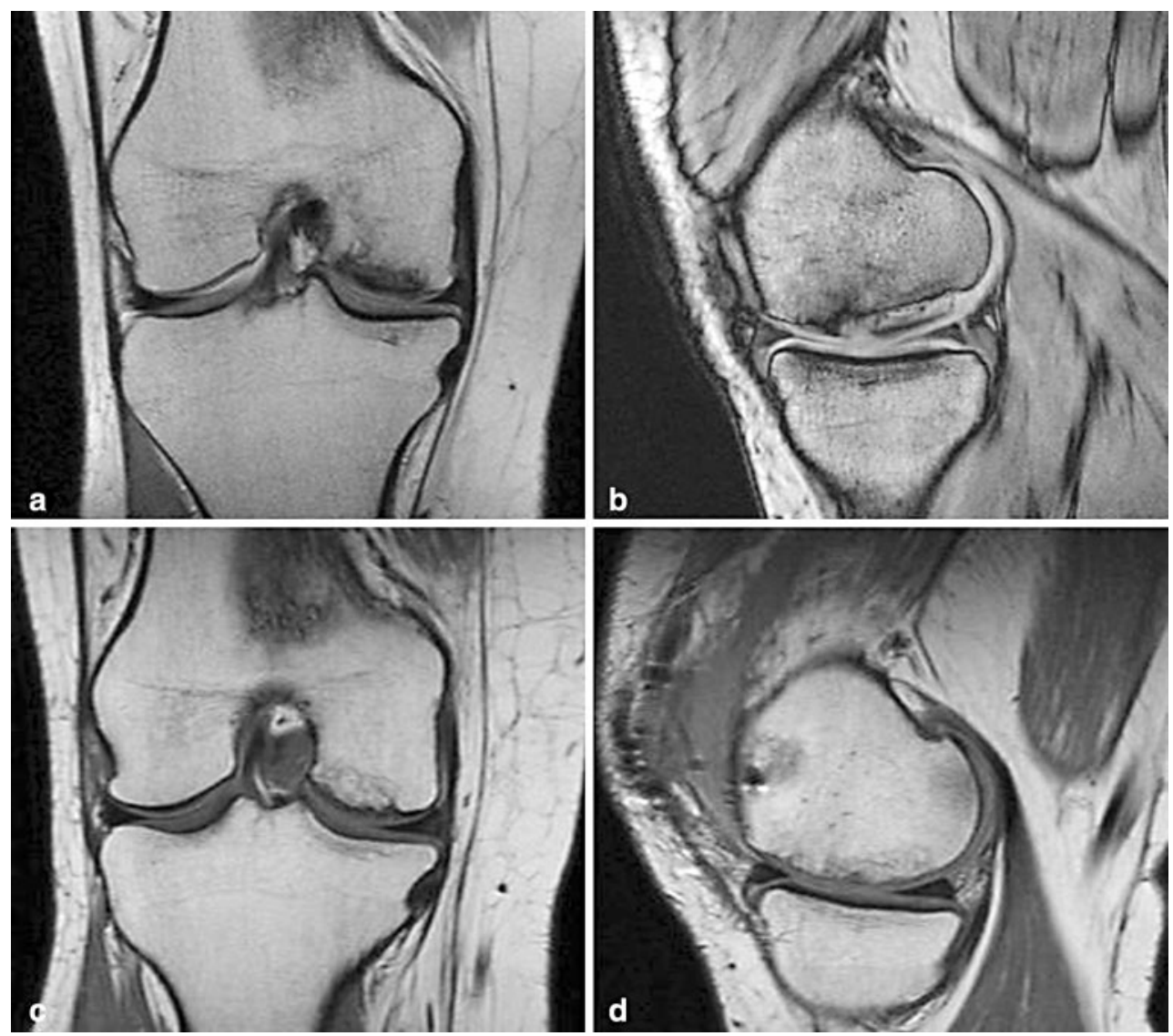

Fig. 2 MRI images of a 31-year-old female patient treated by combined autologous bone grafting and GACI. a Preoperative coronal T1-weighted spin-echo MR image and b sagittal T1-weighted gradient echo MR image shows a severe osteochondral defect (ICRS IV) of the medial condyle in the weight-bearing zone. At 3 months

Bone grafting is necessary to fill up the osseous defect to the level of the subchondral bone plate. Usually, the proximal tibia or iliac crest has been utilized as sources for autograft bone. Unfortunately, these harvest sites are associated with substantial postoperative pain, morbidity and additional surgical exposure [3,35]. These disadvantages can be avoided using the ipsilateral distal femur as the source of autograft bone, thereby circumventing a second surgical site; the corticospongious autograft bone can be harvested 'around the corner' of the cartilage edge. The autograft is harvested en block with an osteotome and subsequently size-matched by hand according to the preoperative acquired aluminium foil template. The spongious part of the graft is impacted at the internal site of the defect to facilitate bone ingrowth. If necessary, additional morselized spongious bone chips can be impacted below the corticospongious graft to level the graft surface to the joint surface. The cortical surface of the graft is placed at the outer site and replaces the original subchondral bone plate. Small superficial holes are made in the cortical surface to stimulate fixation and regeneration of the applied GACI.

postoperative follow-up, the bone repair tissue of the bone graft shows remodelling, and the signal intensity of the transplanted cartilage is comparable with the adjacent cartilage on the postoperative $\mathbf{c}$ coronal and $\mathbf{d}$ sagittal T1-weighted MR images

Since the cortical surface of the corticospongious graft originates from an anatomically slight convex cortical surface of the distal femoral condyle, there were no difficulties in using this corticospongious graft for convex subchondral surface reconstruction of the articular knee joint. In addition, some further moulding of the thin cortex in a convex surface proved to be possible.

Surface cartilage repair by ACI has been introduced for focal cartilage repair $[7,8,21,31,34]$. This technique encompasses culturing autologous chondrocytes for four to 6 weeks, and subsequent implantation below a periosteal patch (ACI-P) $[7,8,31]$ or a porcine collagen patch (ACIC) $[21,31]$ sutured and sealed with fibrin glue over the defect. Good results have been reported with these techniques for the treatment of focal cartilage defects up to four square $\mathrm{cm} \mathrm{[21,} \mathrm{28,} \mathrm{31,} \mathrm{34].} \mathrm{However,} \mathrm{the} \mathrm{treatment} \mathrm{of}$ osteochondral defects of the distal femur condyle by combined bone grafting and ACI-P or ACI-C has been described in only a few papers. Peterson et al. [28] described a "sandwich technique" in 7 out of 58 patients treated for symptomatic osteochondral defects of the knee. 
In this procedure, cancellous bone from the iliac crest or from the proximal-medial part of the tibia was harvested and covered with two periosteal membranes. Subsequently, autologous chondrocytes were injected between the two periosteal layers. Bartlett et al. [5] described a variation in this method using a bilayer porcine collagen matrix seeded with chondrocytes to cover the applied bone graft in 8 patients. All 8 patients showed a significant improvement on the Cincinatti score 6 months postoperatively, and 5 patient were available for 1-year follow-up. At 1-year follow-up, 4 out of these 5 patients demonstrated good or excellent results [5]. Ochs et al. [25] described the results of a two to 5-year follow-up of 26 patients with symptomatic osteochondral defects of the knee. The defect was filled up with monocortical cancellous cylinders, harvested from the iliac crest. The cylindrical cortical graft layers served as novel subchondral bone plate, which was subsequently covered with a chondrocyte-seeded matrix fixated with sutures. At final follow-up, $73 \%$ of all patients demonstrated good or excellent results [25]. Finally, Krishnan et al. [21] reported the 2- to 7-year result of 37 patients treated by ACI-C for symptomatic osteochondral defects of the knee. However, only one patient was treated by combined bone grafting and ACI-C.

To our best knowledge, the use of a gel-type ACI (GACI) in combination with bone grafting for severe unstable osteochondral defects of the knee has not been reported before. GACI has been introduced as an alternative ACI procedure for the repair of focal cartilage lesions of the knee $[10,18,19,37]$. The fibrin gel fills up to the exact shape of the chondral lesion and polymerizes within $3 \mathrm{~min}$ after application. The use of GACI without using a periosteal or collagen patch reduces surgical difficulties associated with fixation and sealing of the patch to the intact cartilage edge. In addition, the gel facilitates the attachment and distribution of the cultured chondrocytes in the defect. Finally, a lower incidence of graft-associated complications such as fibrillation, hypertrophy or delamination has been reported in GACI when compared to ACI-P [10, 14, 18, 29, 38].

During surgery, the stability of the graft and GACI was tested by passive flexion and extension of the knee joint. If the graft and GACI adequately remains in the defect site, the surgery was finished. Immediate postoperative brace immobilization of the knee in extension is advised. In addition, early intermitted CPM has been used for rehabilitation, as recommended by Salter et al. [30]. Immediate postoperative CPM has beneficial effects on cartilage healing. In addition, it has been shown that CPM promotes postoperative wound healing following arthrotomy [33].

One failure following the treatment of a severe osteochondral defect of the knee by GACI combined with autologous bone grafting was experienced. This 39-yearold female suffered from a traumatic osteochondral defect
6 years before she entered our study. A reason for this failure may have been the development of secondary osteoarthritis of the medial femur condyle during these years. Therefore, local treatment of the osteochondral defect of this patient by GACI was not possible anymore and failed. The patient was treated with an unicompartmental knee arthroplasty 1 year after GACI treatment. Conversion to a total or unicompartmental knee arthroplasty is warranted when the clinical symptoms and additional imaging suggest treatment failure. A second-look arthroscopy in all treated patients combined with biopsy of the grafted surface would enable us to determine the histological quality of the restorative tissue, but due to ethical considerations, this was not performed in this patient group.

Limitations of this study are the small number of patients and short follow-up time. However, the incidence of patients with severe symptomatic and unstable osteochondral defects of the knee is (fortunately) low. Therefore, a larger prospective controlled study is necessary to evaluate the advantages of this technique compared to combined autologous bone grafting and ACI-C or ACI-P as a treatment option for severe and unstable osteochondral defects of the knee.

\section{Conclusion}

Combined autologous bone grafting and a gel-type ACI (GACI) may offer an alternative and technically less demanding surgical option for severe and unstable osteochondral defects of the knee.

Acknowledgments Special thanks to N. B. D. Gilhuijs, MD, Department of Pathology of the Medical Centre Alkmaar (MCA), The Netherlands.

Conflict of interest The authors declare that they have no competing interests.

Open Access This article is distributed under the terms of the Creative Commons Attribution License which permits any use, distribution, and reproduction in any medium, provided the original author(s) and the source are credited.

\section{References}

1. Aglietti P, Ciardullo A, Giron F, Ponteggia F (2001) Results of arthroscopic excision of the fragment in the treatment of osteochondritis dissecans of the knee. Arthroscopy 17:741-746

2. Anderson AF, Irrgang JJ, Kocher MS, Mann BJ, Harrast JJ (2006) The International Knee Documentation Committee subjective knee evaluation form: normative data. Am J Sports Med 34:128-135

3. Barone A, Ricci M, Mangano F, Covani U (2011) Morbidity associated with iliac crest harvesting in the treatment of maxillary and mandibular atrophies: a 10-year analysis. J Oral Maxillofac Surg 69:2298-2304 
4. Barrie HJ (1987) Osteochondritis dissecans 1887-1987. A centennial look at Konig's memorable phrase. J Bone Joint Surg Br 69:693-695

5. Bartlett W, Gooding CR, Carrington RW, Skinner JA, Briggs TW, Bentley G (2005) Autologous chondrocyte implantation at the knee using a bilayer collagen membrane with bone graft. A preliminary report. J Bone Joint Surg Br 87:330-332

6. Benthien JP, Behrens P (2011) The treatment of chondral and osteochondral defects of the knee with autologous matrix-induced chondrogenesis (AMIC): method description and recent developments. Knee Surg Sports Traumatol Arthrosc 19:1316-1319

7. Bentley G, Biant LC, Carrington RW, Akmal M, Goldberg A, Williams AM, Skinner JA, Pringe J (2003) A prospective, randomised comparison of autologous chondrocyte implantation versus mosaicplasty for osteochondral defects in the knee. J Bone Joint Surg Br 85:223-230

8. Brittberg M, Lindahl A, Nilsson A, Ohlsson C, Isaksson O, Peterson L (1994) Treatment of deep cartilage defects in the knee with autologous chondrocyte transplantation. N Engl J Med 331:889-895

9. Brittberg M, Winalski CS (2003) Evaluation of cartilage injuries and repair. J Bone Joint Surg Am 85-A(Suppl 2):58-69

10. Choi NY, Kim BW, Yeo WJ, Kim HB, Suh DS, Kim JS, Kim YS, Seo YH, Cho JY, Chun CW, Park HS, Shetty AA, Kim SJ (2010) Gel-type autologous chondrocyte (Chondron) implantation for treatment of articular cartilage defects of the knee. BMC Musculoskelet Disord 11:103

11. de Groot I, Favejee MM, Reijman M, Verhaar JA, Terwee CB (2008) The Dutch version of the knee injury and osteoarthritis outcome score: a validation study. Health Qual Life Outcomes 6:16

12. Gomoll AH, Flik KR, Hayden JK, Cole BJ, Bush-Joseph CA, Bach BR Jr (2007) Internal fixation of unstable Cahill Type-2C osteochondritis dissecans lesions of the knee in adolescent patients. Orthopedics 30:487-490

13. Gomoll AH, Madry H, Knutsen G, van Dijk N, Seil R, Brittberg M, Kon E (2010) The subchondral bone in articular cartilage repair: current problems in the surgical management. Knee Surg Sports Traumatol Arthrosc 18:434-447

14. Gooding CR, Bartlett W, Bentley G, Skinner JA, Carrington R, Flanagan A (2006) A prospective, randomised study comparing two techniques of autologous chondrocyte implantation for osteochondral defects in the knee: periosteum covered versus type I/III collagen covered. Knee 13:203-210

15. Gudas R, Kalesinskas RJ, Kimtys V, Stankevicius E, Toliusis V, Bernotavicius G, Smailys A (2005) A prospective randomized clinical study of mosaic osteochondral autologous transplantation versus microfracture for the treatment of osteochondral defects in the knee joint in young athletes. Arthroscopy 21:1066-1075

16. Hangody L, Fules P (2003) Autologous osteochondral mosaicplasty for the treatment of full-thickness defects of weightbearing joints: ten years of experimental and clinical experience. J Bone Joint Surg Am 85-A(Suppl 2):25-32

17. Hefti F, Beguiristain J, Krauspe R, Möller-Madsen B, Riccio V, Tschauner C, Wetzel R, Zeller R (1999) Osteochondritis dissecans: a multicenter study of the European pediatric orthopedic society. J Pediatr Orthop B 8:231-245

18. Kim MK, Choi SW, Kim SR, Oh IS, Won MH (2010) Autologous chondrocyte implantation in the knee using fibrin. Knee Surg Sports Traumatol Arthrose 18:528-534

19. Kim SJ, Chang CH, Suh DS, Ha HK, Suhl KH (2009) Autologous chondrocyte implantation for rheumatoid arthritis of the knee: a case report. J Med Case Reports 3:6619

20. Koch S, Kampen WU, Laprell H (1997) Cartilage and bone morphology in osteochondritis dissecans. Knee Surg Sports Traumatol Arthrosc 5:42-45

21. Krishnan SP, Skinner JA, Carrington RW, Flanagan AM, Briggs TW, Bentley G (2006) Collagen-covered autologous chondrocyte implantation for osteochondritis dissecans of the knee: two- to seven-year results. J Bone Joint Surg Br 88:203-205

22. Lintz F, Pujol N, Pandeirada C, Boisrenoult P, Beaufils P (2011) Hybrid fixation: evaluation of a novel technique in adult osteochondritis dissecans of the knee. Knee Surg Sports Traumatol Arthrosc 19:568-571

23. Millington KL, Shah JP, Dahm DL, Levy BA, Stuart MJ (2010) Bioabsorbable fixation of unstable osteochondritis dissecans lesions. Am J Sports Med 38:2065-2070

24. Murray JR, Chitnavis J, Dixon P, Hogan NA, Parker G, Parish EN, Cross MJ (2007) Osteochondritis dissecans of the knee; longterm clinical outcome following arthroscopic debridement. Knee 14:94-98

25. Ochs BG, Müller-Horvat C, Albrecht D, Schewe B, Weise K, Aicher WK, Rolauffs B (2011) Remodeling of articular cartilage and subchondral bone after bone grafting and matrix-associated autologous chondrocyte implantation for osteochondritis dissecans of the knee. Am J Sports Med 39:764-773

26. Pappas AM (1981) Osteochondrosis dissecans. Clin Orthop Relat Res 158:59-69

27. Pascual-Garrido C, Friel NA, Kirk SS, McNickle AG, Bach BR Jr, Bush-Joseph CA, Verma NN, Cole BJ (2009) Midterm results of surgical treatment for adult osteochondritis dissecans of the knee. Am J Sports Med 37(Suppl 1):125S-130S

28. Peterson L, Minas T, Brittberg M, Lindahl A (2003) Treatment of osteochondritis dissecans of the knee with autologous chondrocyte transplantation: results at two to ten years. J Bone Joint Surg Am 85-A(Suppl 2):17-24

29. Rosenberger RE, Gomoll AH, Bryant T, Minas T (2008) Repair of large chondral defects of the knee with autologous chondrocyte implantation in patients 45 years or older. Am J Sports Med 36:2336-2344

30. Salter RB, Simmonds DF, Malcolm BW, Rumble EJ, MacMichael D, Clements ND (1980) The biological effect of continuous passive motion on the healing of full-thickness defects in articular cartilage. An experimental investigation in the rabbit. J Bone Joint Surg Am 62:1232-1251

31. Saris DB, Vanlauwe J, Victor J, Almqvist KF, Verdonk R, Bellemans J, Luyten FP; TIG/ACT/01/2000\&EXT Study Group (2009) Treatment of symptomatic cartilage defects of the knee: characterized chondrocyte implantation results in better clinical outcome at 36 months in a randomized trial compared to microfracture. Am J Sports Med 37(Suppl 1):10S-19S

32. Schenck RC Jr, Goodnight JM (1996) Osteochondritis dissecans. J Bone Joint Surg Am 78:439-456

33. van Royen BJ, O'Driscoll SW, Dhert WJ, Salter RB (1986) A comparison of the effects of immobilization and continuous passive motion on surgical wound healing in mature rabbits. Plast Reconstr Surg 78:360-368

34. Vasiliadis HS, Wasiak J (2010) Autologous chondrocyte implantation for full thickness articular cartilage defects of the knee. Cochrane Database Syst Rev 10:CD003323

35. Winson IG, Higgs A (2010) The use of proximal and distal tibial bone graft in foot and ankle procedures. Foot Ankle Clin 15:553-558

36. Wright RW, McLean M, Matava MJ, Shively RA (2004) Osteochondritis dissecans of the knee: long-term results of excision of the fragment. Clin Orthop Relat Res 424:239-243

37. Wysocka A, Mann K, Bursig H, Dec J, Gazdzik TS (2010) Chondrocyte suspension in fibrin glue. Cell Tissue Bank 11:209-215

38. Zaslav K, Cole B, Brewster R, DeBerardino T, Farr J, Fowler P, Nissen C, STAR Study Principal Investigators (2009) A prospective study of autologous chondrocyte implantation in patients with failed prior treatment for articular cartilage defect of the knee: results of the Study of the Treatment of Articular Repair (STAR) clinical trial. Am J Sports Med 37:42-55 